\title{
Paradigms for Employing Interactive Computing Tools and Graphical User Interfaces (GUIs) in Structural Engineering Problems
}

\author{
Fawad Ahmed Najam, Rao Arsalan Khushnood, and Syed Ali Rizwan
}

\begin{abstract}
The development of intelligent computational tools provides new opportunities to exploit various potentialities of computers. Many fields have taken significant advantage of the recent advancements in computing technology to adapt, apply and enhance the way people learn and solve real-world problems. In this paper, three case studies are presented which show how the development of knowledge-based computer applications can be handy to both understand and solve structural engineering numerical problems. Moreover, such tools can be useful teaching aids and can facilitate interactive learning techniques being used across the globe. The first case study application is a graphical user interface (GUI) developed in MATLAB 2009 environment for dynamic analysis of a generalized single degree of freedom system against specified force vector or ground motion. The second example is from the field of reinforced concrete design developed in Visual Basic environment for generating moment curvature relationship of reinforced concrete beams. The third case study application is also developed in MATLAB R2009a environment using GUIDE module to automate a recently proposed empirical method of concrete mix design. These interfaces are developed in a simple and interactive manner for convenient visualization of complete step-by-step process aiming not only to provide an easy tool for what-if analysis, but also to develop a learning attitude among the end users.
\end{abstract}

Index Terms-Computational tools, visual basic, computer applications, structural engineering, mix design, MATLAB, GUI.

\section{INTRODUCTION}

In engineering and other technological fields, the growth and development in the application of computing tools and technologies, and the development of new paradigms has been incremental and linear. The old learning paradigm was about what software/tools can do while the new paradigm is all about what users can do [1]. Often the developments which are going on, in various fields related to computing software and hardware are done independently with a particular focus. The wide spread use of internet, intranet and more recently cloud computing is changing the way

Manuscript received June 13, 2014; revised August 23, 2014. This paper was thankful to AIT Consulting (Thailand) and NUST (Pakistan) for providing funding, excellent research environment and facilities.

Fawad Ahmed Najam is with Asian Institute of Technology (AIT), Thailand (e-mail: fawadnajam@hotmail.com).

Rao Arsalan Khushnood is with Politecnico Di Torino, Italy (email: rao_nust@yahoo.com)

Syed Ali Rizwan is with the Structural Engineering Department, NUST Institute of Civil Engineering (NICE), National University of Sciences \& Technology (NUST), Sector H-12, Islamabad, Pakistan (e-mail: syedalirizwan@hotmail.com). computers are being used, and information is being shared and stored [2]. The availability of latest computational platforms, simulation tools, analysis packages and World Wide Web (WWW) have now changed the way engineers deal with real life problems by helping them become actively engaged in collaborative work via various computer-supported processes. This paper highlights some areas of structural engineering where knowledge-based applications can be used to enhance understanding as well as to provide ease in quick problem solving.

\section{EMERGING TECHNOLOGIES AND TOOLS}

Many fields have taken significant advantage of the recent advancements in the technologies related to computing and communications which are happening in an exponential manner, especially when considered along with their reduction in cost per feature or capability. Traditional computers including desktops and workstations are being replaced by laptops, notebooks, smart pads, and tablets. Development of wide range of delicate instruments and sensors (accelerometers, inclinometers, light sensors, noise sensors and many more) integrated with attractive 3D displays may prove to be very handy for field civil engineers [2]. Information and data sharing, access and transfer has gone through a revolutionary change with the emergence of modern mobility, wireless connectivity devices and access technologies over the last few decades. Social media have made it possible to get in touch with work groups around the clock, no matter where you are. Online journals, blogs, newsgroups, digital libraries and search engines are available to find the relevant information in abundance. In the computing field, Artificial Neural Networks (ANN), Fuzzy Logic, Genetic Algorithms (GA), Optimization etc. are some important and powerful tools applied to solve difficult problems with a different and appealing approach. Remarkable efforts are being done in various walks of life to absorb this innovatory change and to make best use of the modern computing technologies and devices [3].

\section{COMPUTATIONAL PARAdigMS IN STRUCTURAL ENGINEERING}

Modern computing techniques and devices are now playing their role in various structural engineering fields also. With the increasing interest in building information modeling (BIM) in the industry, various model-based applications have been introduced to facilitate the professionals. 


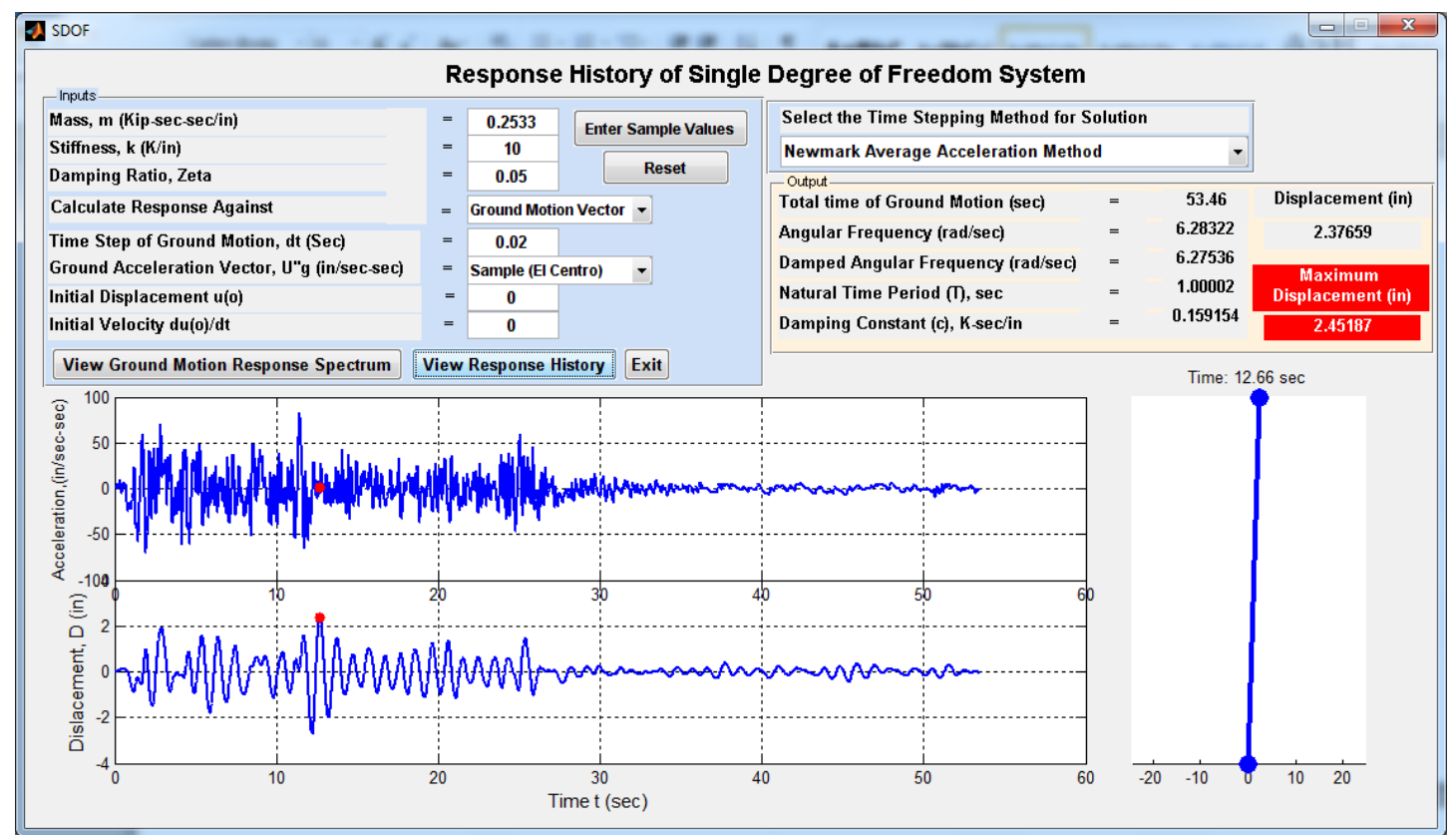

(a) Main Interface.

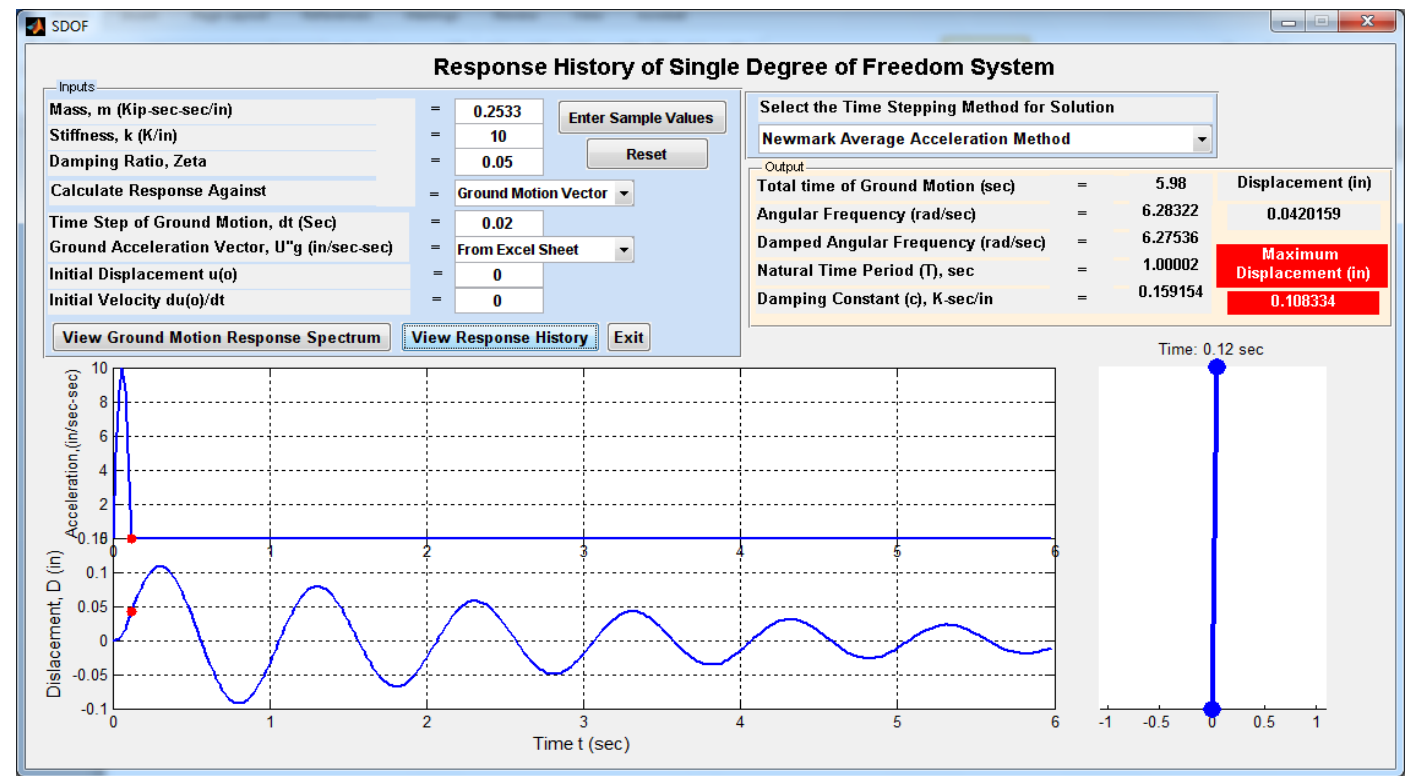

(b) Response of a SDOF system against an impulse ground motion.

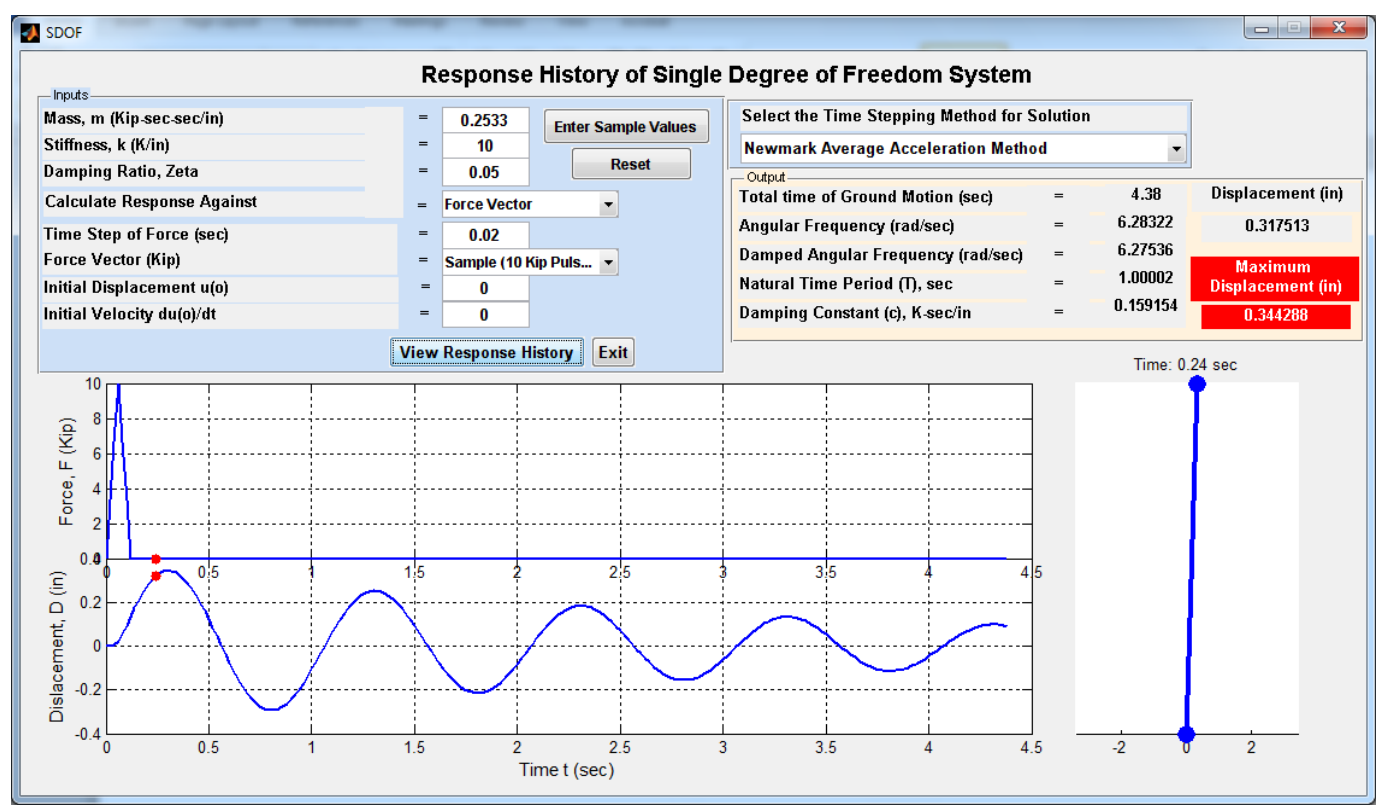

(c) Response of a SDOF system against an impulse force vector. 


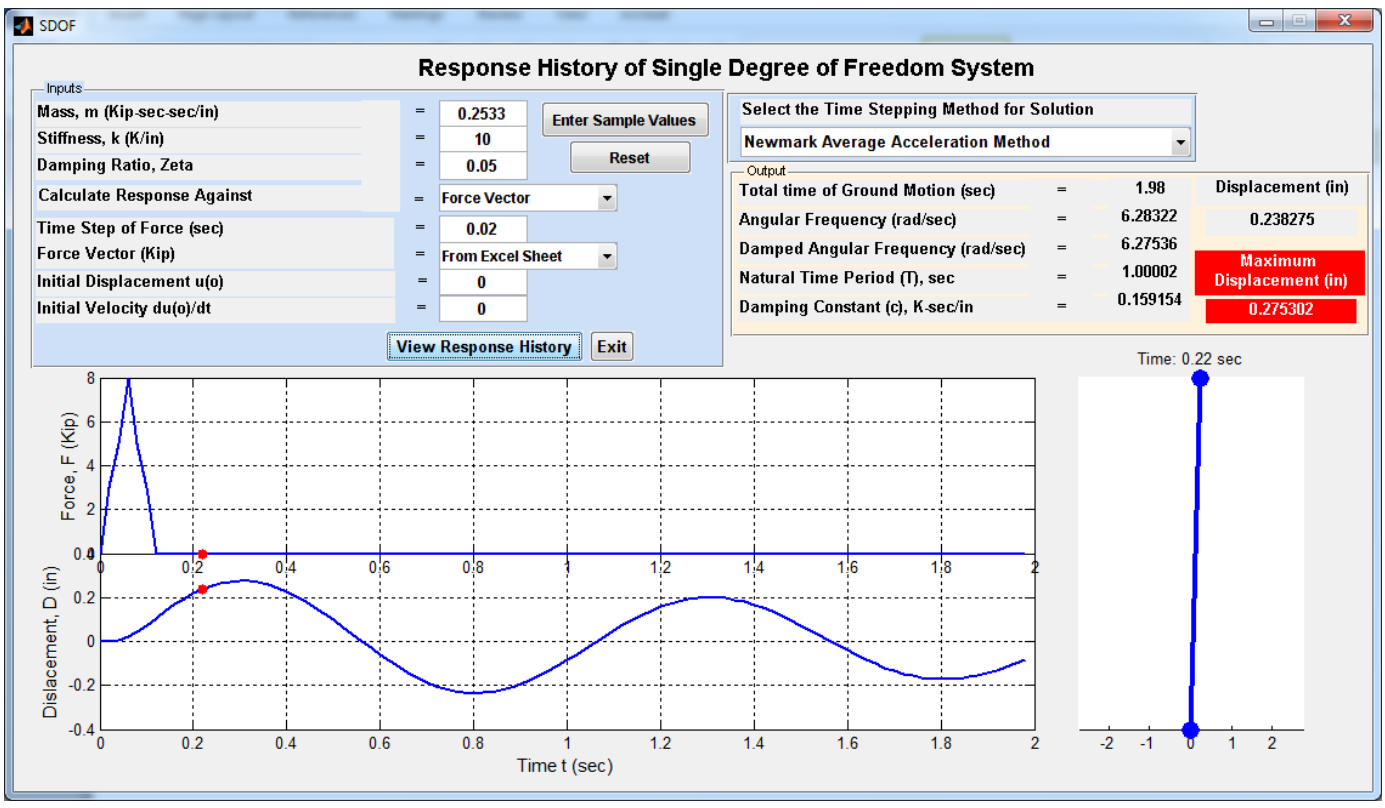

(d) Response of a SDOF system against an impulse force vector defined in a separate file.

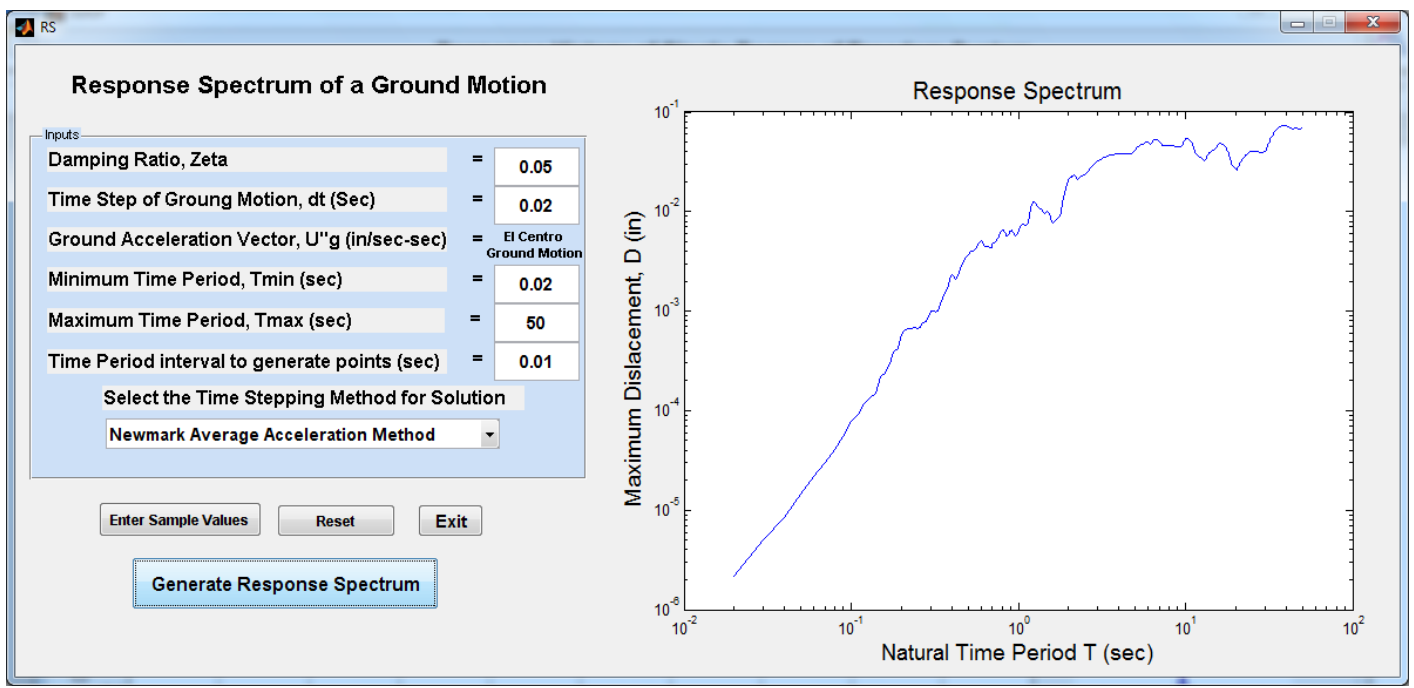

(e) A separate module to generate elastic response spectrum of ground motions.

Fig. 1. Case study 1 - response of single-degree-of-freedom system against force or ground motion.

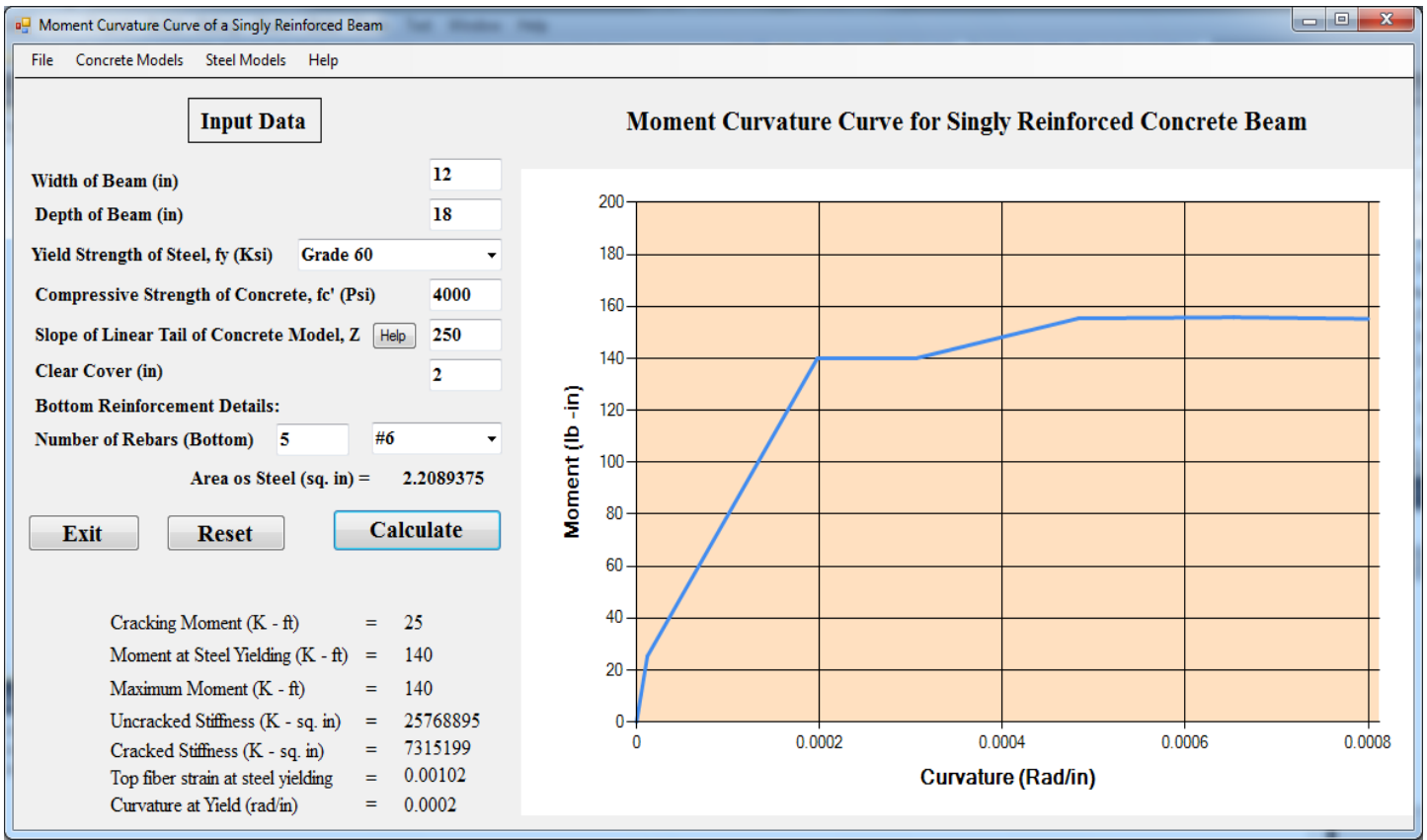

(a) Main interface. 


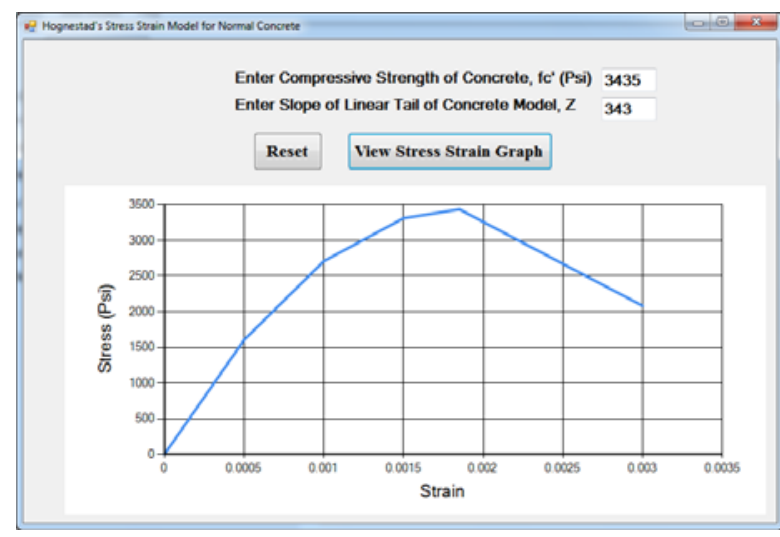

(b) Stress-strain model for concrete [15].

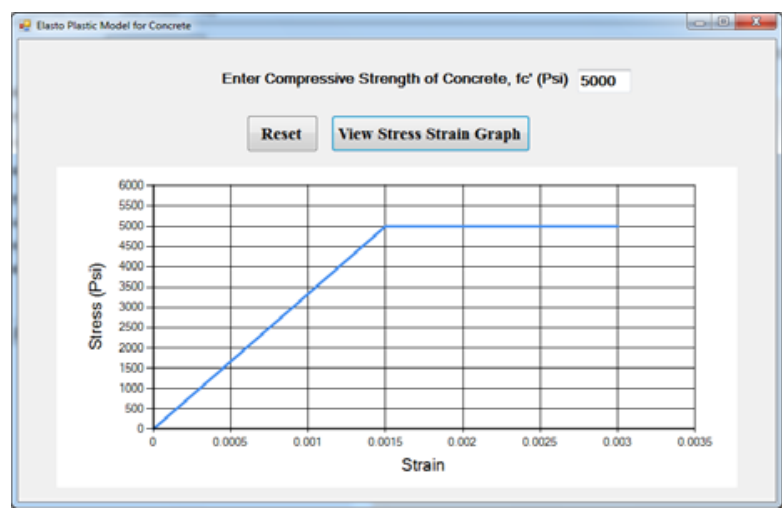

(c) Stress-strain model for concrete (elastoplastic [15]).

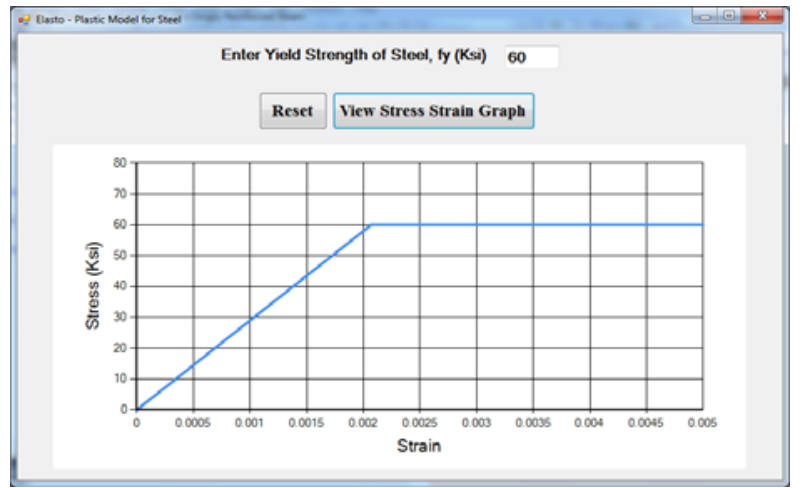

(d) Stress-strain model for steel (elastoplastic [15]).

Fig. 2. Case study 2 - predicting moment-curvature response of a reinforced beam element.

Apart from the fact that structural engineers were in fact one of the pioneers and originators of application of computing systems and methods (like Finite Element Method) [2], it seems that in structural engineering the modernization of computing techniques and devices have not kept reasonable pace. Many other professions and fields have adapted modern computing practices very swiftly. Medical sciences is one of the examples where these practices have brought astonishing development and ease. The obstacles in structural engineering are numerous and complex, and just like medical sciences also related to safety and livability of human beings. Introduction of modern computation methods and devices in structural engineering can be very handy and useful, resulting in amazing ease for structural engineers in terms of solving complex nature problems. Therefore, for structural engineers, it is need of the hour to embrace modernized computing techniques and devices, not only to generate and provide answers to ever increasing number and nature problems but also to match up with the pace of the development booming around us [4].

Currently most of the structural engineers are using the traditional computing programs and techniques to solve problems especially while designing structures and usually it is difficult to visualize the results or output of the analysis carried out. Sometimes after a successful analysis, it is difficult to present the output in an understandable way. For this purpose visualization techniques are now being applied to communicate the message by creating images, diagrams or animations [2]. Now, with the help of advance finite element solvers, it is possible to perform various analysis and activities in a shorter period of time including preliminary designing for initial sizing of members, nonlinear modeling, graphical representation and visualization of the analysis output, generating Building Information Model (BIM) to present and visualize building components, construction sequences, resource allocation and other disciplines of construction process in a virtual environment. In earlier generation structural engineering programs, user had to specify the nodal coordinates, member incidences, material and sectional properties, loads as well as the support conditions. The program then calculated the member forces, nodal reactions and joint displacements and presented in a tabular format. However, modern day structural analysis programs far more computationally powerful and at the same time, easy to use. Now user can develop models for any number of degrees of freedom, apply loads and boundary conditions on screen using mouse clicks in a graphical mode. In outputs, user can visualize the stresses on various elements in all directions, shear force, bending moment and deflected shapes. Nowadays various commercially available packages including ETABS, SAP2000, STAAD Pro, SAFE, Auto CAD, ANSYS, ABAQUS, PERFORM 3D and others serve the above mentioned purposes. However, a structure will not (and is not supposed to) behave "exactly" as the computer program tells it should, regardless of how accurate the program seems. On the other side, open source tools and frameworks like "OpenSees" (Open System for Earthquake Engineering Simulation) allows users to create object-oriented applications for simulating the response of structural and geotechnical systems subjected to earthquakes $[5]$.

Similarly, with the evolution of mesh-less methods for structural analysis, various other advancements in finite element analysis and performance-based design procedures, the importance of high-speed computing and enhanced processing units has increased exponentially [2]. On the other side, the development of integrated sensors, radio-frequency identification (RFID), global positioning system (GPS), wireless and other technologies are being used for real-time monitoring of the structural response, both for ambient conditions and during events such as strong winds, earthquakes, moving loads, temperature and moisture changes etc. These sensors can also be employed to track and monitor the time dependent phenomena such as shrinkage, creep, concrete aging, degradation, ionization, chlorine attack and link these inputs to the structural models to produce meaningful response that can be communicated to the owners, public and researches in real time [3]. Material 
behavior simulation has now become more demanding with the advent of smart materials including piezoelectric and magnetostrictive materials, shape-memory alloys, temperature-responsive polymers, chromogenic systems (electrochromic, thermochromic and photochromic), self-healing materials and dielectric elastomers (DEs) [6].

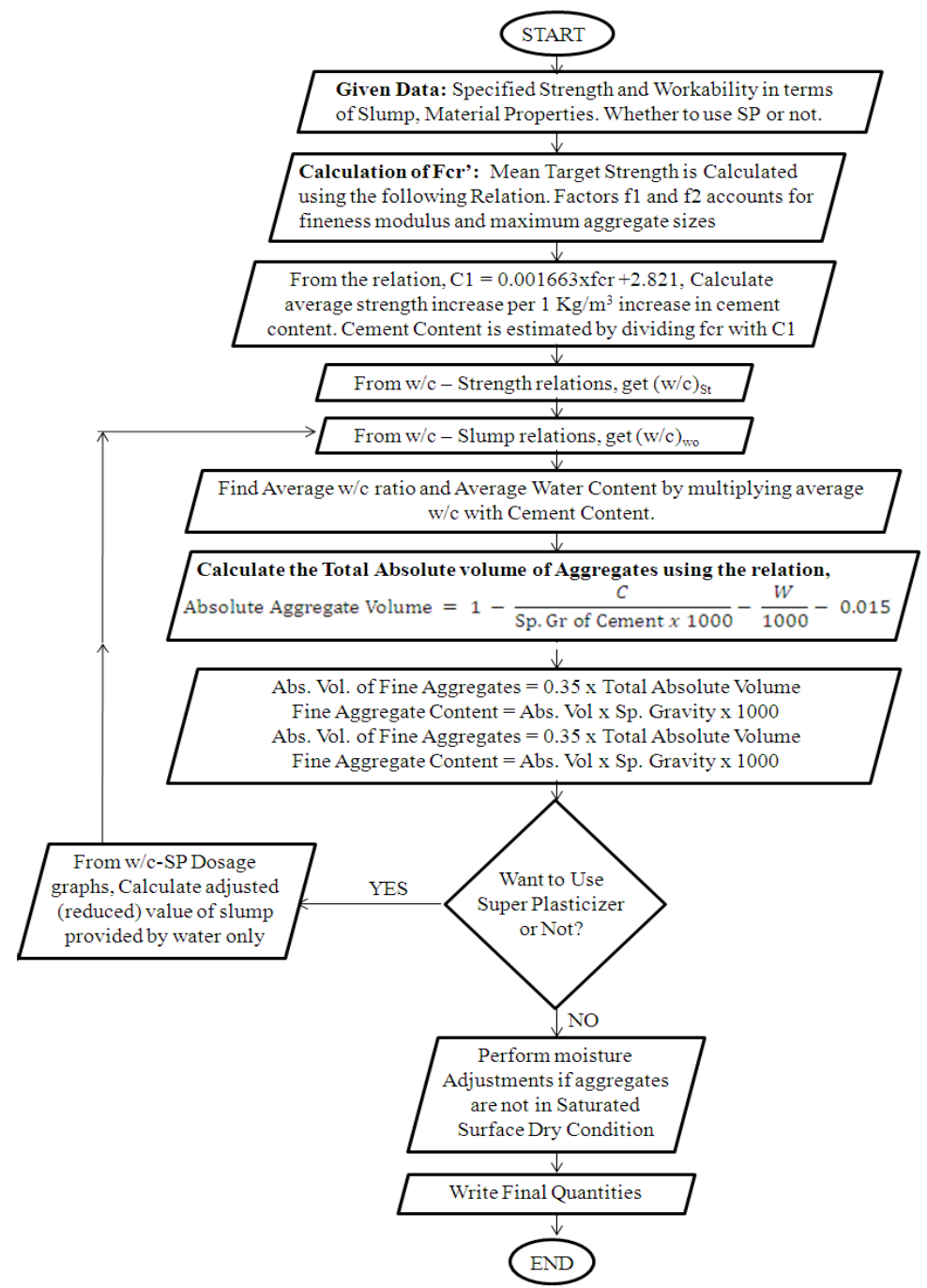

(a) Flow chart for the mix design method to be implemented.

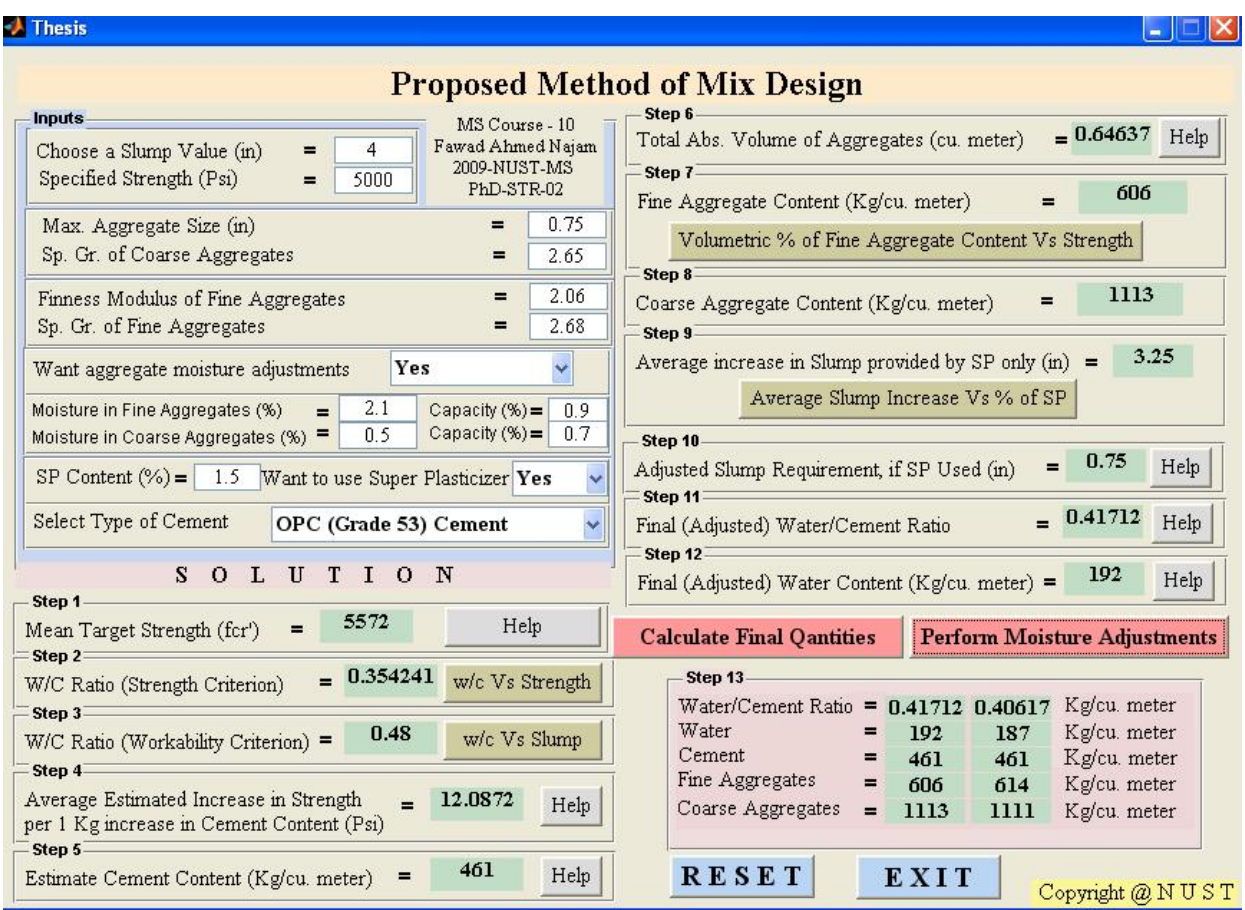

(b) Main interface. 


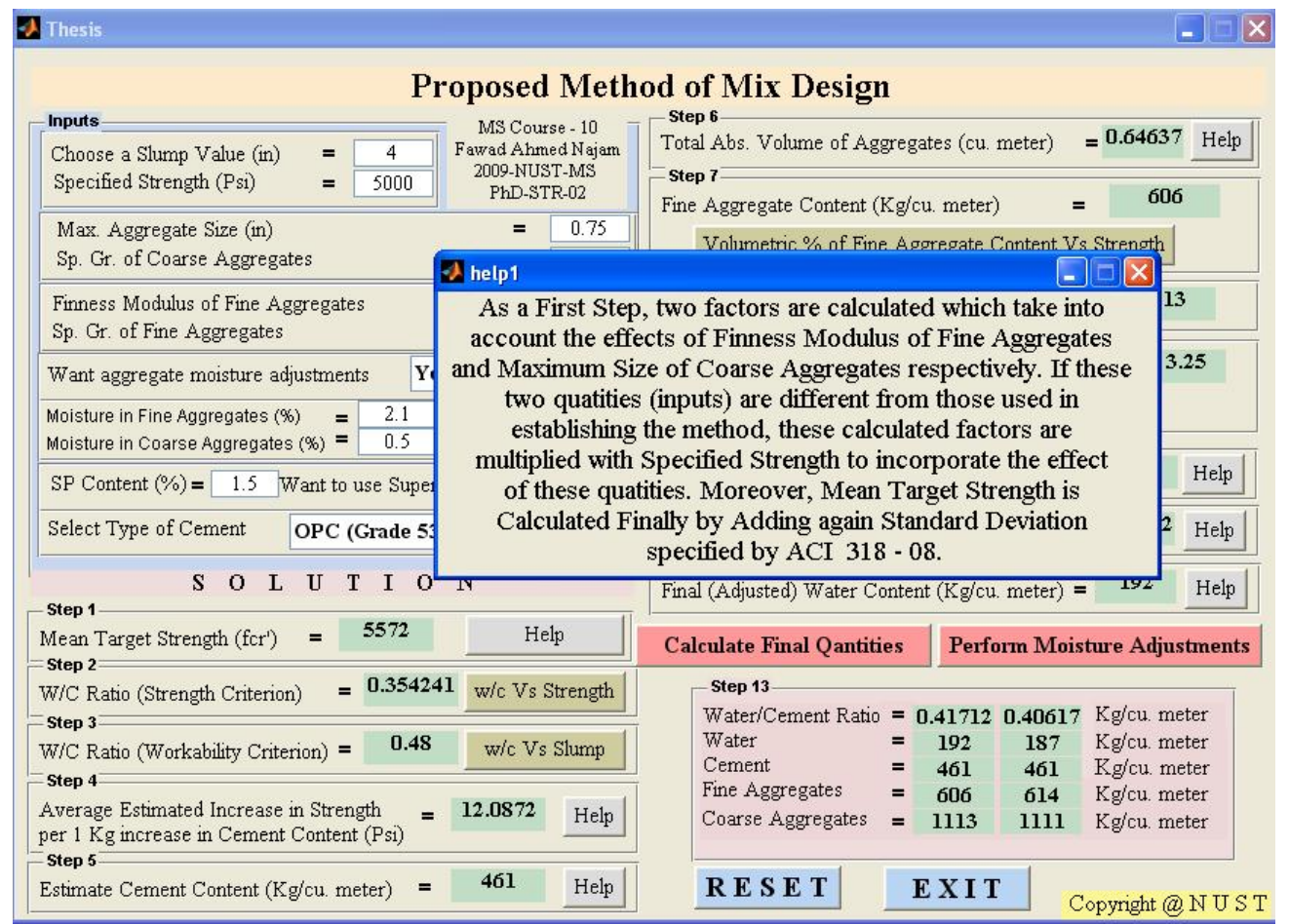

(c) Using "help" buttons.

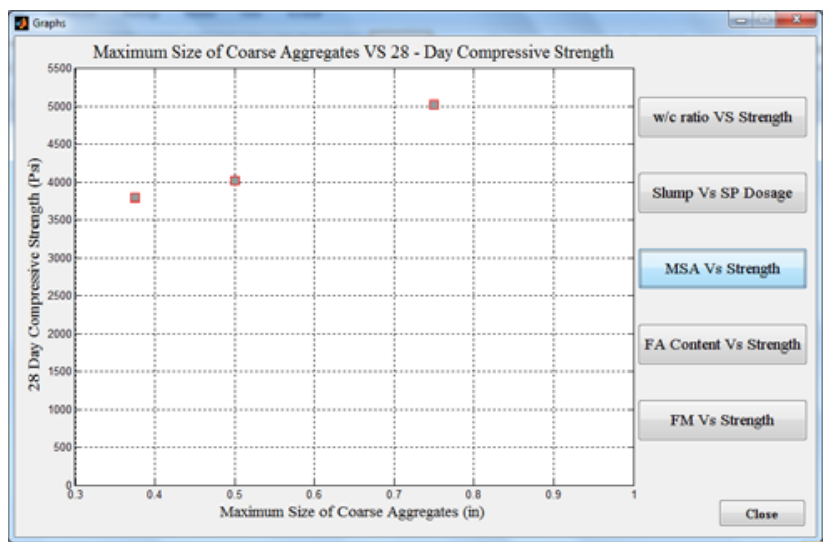

(d) Relationship between maximum aggregate size and 28-day compressive strength of concrete.

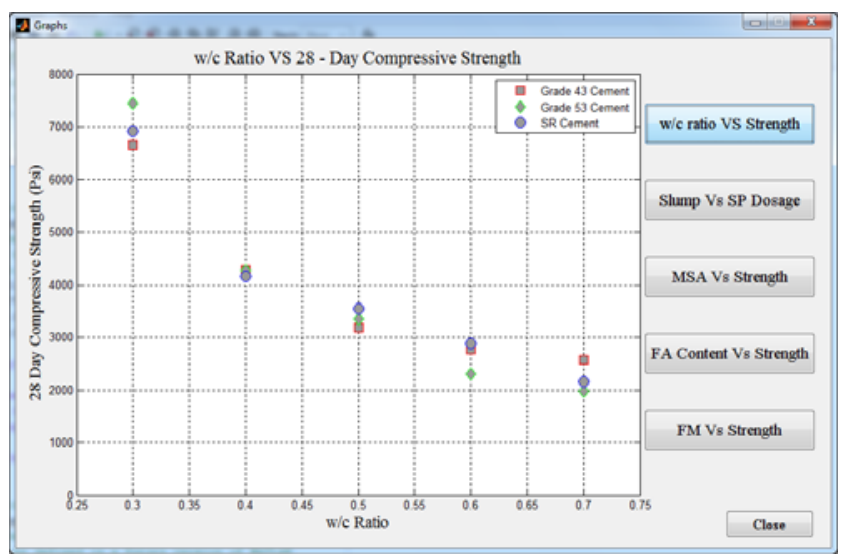

(e) Relationship between water-to-cement ratio and 28-day compressive strength of concrete for three commonly used cement types in Pakistan.

Fig. 3. Case study 3 - computer aided mix design of concrete.

\section{GRAPHICAL USER INTERFACES (GUI) AND ITS ELEMENTS}

The interaction between users and computers occurs at the "user interface" (or simply interface), which includes both software and hardware; for example, characters or objects displayed by software on a personal computer's monitor, input received from users via hardware peripherals such as keyboard and mouse, and other user interactions with large-scale computerized systems such as aircraft and power plants. In software development field, the term GUI or "graphical user interface" is used to refer a pictorial interface and a point of contact between the user and the computer program [7]. It provides a convenient environment with the help of its components, figures and callbacks. It allows users to interact with electronic devices using images, symbols, visual metaphors, and pointing devices rather than text commands. A GUI represents the information and actions available to a user through graphical icons and visual indicators as opposed to typed command labels or text navigation. Designing the visual composition and temporal behavior of GUI is an important part of software application programming in the area of human-computer interaction (HCI). Its goal is to enhance the efficiency and ease of use for the underlying logical design of a stored program. Typically, the user interacts with information by manipulating visual widgets that allow for interactions appropriate to the kind of data they hold. A widget is an element of GUI that displays an information arrangement changeable by the user, such as a window or a text box etc. The defining characteristic of a widget is to provide a single interaction point for the direct manipulation of a given kind of data [8].

The goal of user interface design is to make the user's interaction as simple and efficient as possible, in terms of accomplishing user requirements. The design process must balance technical functionality and visual elements to create a system that is not only operational but also usable and adaptable to changing user needs. Interface design is involved in a wide range of projects from computer systems, to cars, to commercial planes; all of these projects involve 
much of the same basic human interactions yet also require some unique skills and knowledge. As a result, designers tend to specialize in certain types of projects and have skills centered around their expertise, whether that be software design, user research, web design, or industrial design. In visual basic .NET (VB.NET) framework, programmers make extensive use of forms to build user interfaces. For creating a windows application, one has to start with a default blank form in visual studio, onto which, programmers can drag and drop controls from the toolbox window. The basic elements of a typical VB.NET application includes labels, buttons, text boxes, check boxes, combination boxes, list boxes, radio buttons, progress bar and scroll bars. In MATLAB terminology, keyboard inputs or mouse clicks are referred to as events. The code executed in response to an event is known as callback. The components used in GUIs presented in this paper include push-buttons, edit boxes, pop-up menus, frames, and text fields. The developed case study applications respond to each event and implement the functions of each graphical object on the figure window. The code sets in the callbacks may include the regression equations, input and output commands as well as other necessary calculations. A MATLAB GUI consists of following two types of files [9], [10].

1) A FIG-file, with extension .fig, that contains a complete description of the GUI layout and the GUI components, such as push buttons, axes, panels, menus, and so on. The FIG-file is a binary file and user cannot modify it except by changing the layout in a GUI development module of MATLAB known as GUIDE.

2) An M-file, with extension .m, that initially contains initialization code and templates for some callbacks that are needed to control GUI behavior.

Three case studies from various fields of structural engineering will be presented in subsequent sections.

\section{CASe Study 1 - Response of \\ SINGLE-DEGREE-OF-FrEEDOM SYSTEM AGAINST FORCE OR GROUND MOTION}

The first case study application is from the field of structural dynamics. It is a graphical user interface developed in MATLAB 2009 environment for dynamic analysis of a generalized single degree of freedom system against a specific force vector or ground motion. MATLAB is both a computer programming language and a software environment for using that language effectively. Its interactive environment allows the user to manage variables, import and export data, perform calculations, generate plots and develop files [11].

Simple structures like pergola, elevated water tank, and single story frame structures etc. can be idealized as single degree of freedom systems (lumped mass supported by stiffness in the lateral direction) in order to understand the vibration of these structures when subjected to a lateral force at the top or horizontal ground motion due to an earthquake [12]. The energy dissipation by various mechanisms can be idealized by an equivalent viscous damper or dashpot. The damping coefficient is selected so that the vibrational energy it dissipates is equivalent to the energy dissipated in all the damping mechanisms, combined, present in the actual structure [12]. The use of SDOFs in representing a particular mode of vibration is also important in the context of Nonlinear Static Procedures (NSPs). In various NSPs, modal properties of a vibration mode are assigned to a SDOF to get quick response parameters for that particular mode. Equivalent SDOF has now become an integral part of various pushover methods so there is a renewed interest in SDOF solvers which can accommodate a variety of hysteretic behaviors. The presented program is only for linear systems and can provide the end users with elastic demands against a given ground motion however, the code can also be modified to account for elasto-plastic behavior. In case of using more complex and sophisticated models, the commercially available packages and/or open source frameworks based on object oriented programming (e.g. OpenSees) are recommended which require a deep understanding of nonlinear modeling and coding language.

In presented case study application, user is expected to specify the basic inputs including mass, stiffness, damping ratio, time step and initial conditions in input area of interface. Force vector and ground motion must be specified in an MS excel sheet available in same directory from which user can start program. User can also run a sample ground motion (el centro) and a sample force vector (a pulse-like force) in order to understand how the program works and displays results. Two time-stepping methods for solution of governing differential equation of motion are implemented namely, Newmark's constant acceleration method and Newmark's average acceleration method. User can select one method using a drop down menu list and the embedded code will run in a loop for user defined time step and total duration of loading or ground motion (see Fig. 1). The program can also be used to compare the results for these two methods for different ground motions and load vectors. Clicking on "View Response History" will plot two time series. First is the user specified force vector or ground motion and parallel to it, the response of system. So user can see both "picture of force/ground motion" and "picture of response" on a single screen and on two parallel graphs with same time scale. The output also includes natural frequency/time period, damped angular frequency and maximum displacement.

Displacement at any time instant can be picked from time history plot. A moving pointer on both plots (with equal time speed) helps in convenient visualization of time difference between peak force and peak response (or even between two peaks of response). Also a real-time motion of upper node of line model (simulating single degree of freedom) provides an animated view for easy visualization. Clicking "View Ground Motion Response Spectrum" will take user to response spectrum module (Fig. 1. (e)), which plots the displacement response spectrum for input ground motion. Program will run the code for solution of governing differential equation for user defined range of time periods and interval. Peak responses for each run are plotted against natural time period.

\section{Case Study 2 - Predicting Moment-Curvature RESPONSE OF A REINFORCED BEAM ELEMENT}

The second case study application is from the field of 
reinforced concrete design. It is also a graphical user interface developed in VB.NET environment for generating moment-curvature relationship of reinforced concrete beams. Visual Basic .NET (VB.NET) is an object-oriented computer programming language that can be considered an evolution of the classic Visual Basic (VB) language, implemented on the .NET Framework. Microsoft currently supplies two main editions of integrated development environments for developing in Visual Basic namely Microsoft Visual Studio and Visual Basic Express Edition. ".NET" is an integral part of many applications running on Windows and provides common functionality for those applications to run. For developers, the .NET Framework provides a comprehensive and consistent programming model for building applications that have enhanced user experiences.

With the increasing use of higher-grade concretes with lesser ductility, the importance of predicting a reliable moment curvature behavior of structural members has increased significantly which requires a reasonably reliable stress-strain model for each constituent material. With the development of performance-based design methods, there is an increasing need for simplified but reliable analytical tools capable of predicting the flexural behavior of reinforced concrete members [13]. With the advent of state-of-the-art nonlinear modeling techniques, practicing designers will be facing more difficulties and necessity of predicting the deformation capacity of concrete members. The procedure implemented in presented application is given below:

1) A small value of extreme fiber concrete compressive strain $\left(\varepsilon_{c}\right)$ was assumed.

2) The neutral axis depth was assumed initially as a small value.

3) For this value of neutral axis depth, the compressive force in the concrete was calculated from the user-specified stress-strain model.

4) The strain in tension steel was calculated based on the strain compatibility.

5) Based on the strains in tension steels, the corresponding stresses were taken from the user-specified stress-stress model of steel.

6) Increments are applied to neutral axis depth and calculations are repeated for steel and concrete forces until total compressive force become equal to total tensile force.

7) Now, the total moment was calculated as the sum of moments of both compression and tension forces about neutral axis.

8) The corresponding curvature was calculated by dividing initially assumed $\varepsilon_{c}$ by "finalized" neutral axis depth.

These entire steps 1) to 8) were implemented in to a loop for a range of extreme fiber concrete compressive strains $\left(\varepsilon_{c}\right)$ in order to get sufficient points to generate a smooth plot. These values of $\varepsilon_{c}$ were set in the range of 0.0001 up to the failure strain $\left(\varepsilon_{c u}\right)$. User can select and review from two available concrete models namely elastoplastic bilinear and Modified Hognestad's model [14] with linear tail [15]. User can specify the slope of linear tail for Modified Hognestad's Model (Fig. 2).

\section{CASe Study 3 - Computer Aided Mix Design of CONCRETE}

The third case study application is from the field of concrete materials and technology. It is a computer program for a recently proposed empirical method [16] of mix design based on local materials of Pakistan. It is developed in MATLAB R2009a environment using GUIDE module. Using the amazing computational power which MATLAB offers, it is very handy to iterate various variables for optimization purpose. This ability is of key importance in handling the real-life constraints e.g. within a fixed concrete volume, one cannot alter a component independent of others (if the aggregate component is increased, the cement paste component decreases). The task becomes even more complicated by the fact that certain desired properties may be oppositely affected by changing a specific variable. For example, the addition of water to a stiff concrete mixture with a given cement content will improve the flowability of fresh concrete but at the same time will reduce the strength. In fact, workability itself is composed of different components [i.e., consistency (ease of flow), yield stress, cohesiveness (resistance to segregation) and viscosity], and these tend to be affected in an opposite manner when water is added to a given concrete mixture.

The method proposed by ACI 211 [17] Committee for mix design of normal concrete is widely used by practicing engineers, contracting firms as well as academicians. When applied to local aggregate and cement types in Pakistan, a common observation is that quantities recommended by this method as a first trial batch are quite far from quantities which gave desirable characteristics at the end of all trials in laboratory. In general practice, the solution for this cumbersome process of making trials and waiting for 28 or so days was found in development of some thumb rule proportions by contractors for each strength level of concrete. However, no unified study was carried out to address this issue. In a recent study [13], an attempt has been made to address the absence of available data for adjusting trial mixes and an empirical mix design method for local aggregates and cement types was proposed. The presented application fully automates this proposed method and provides optimum proportions for the first trial batch against given performance criteria using easy-to-use graphical user interface.

A very few commercial software packages are available covering various aspects of concrete mix proportioning and trial mix adjustments coupled with experimental data. Employment of intelligent systems and genetic algorithms in concrete materials technology may also provide a solid platform for development of efficient computing tools [18]. In presented program, explanatory notes are also provided as help files to guide the user on decision-making. The main calculating functions and formulae are embedded in two dropdown menu lists i.e. "Selection of Super plasticizer" and "Selection of Cement Type" as shown in Fig. 3. User is expected to provide properties of cement and aggregates including their specific gravities, moisture content in "as stored" conditions, water demands and usage of specific admixture. The required 28-day compressive strength and slump value are the primary input values. The program (based on the regression analysis results of detailed 
experimental program) predicts the quantities to be used in a batch in order to achieve desired input characteristics. Fig. 3 shows some screenshots from various modules of the application.

\section{CONCLUSIONS AND DISCUSSION}

During the last few decades, revolutionary advancement is going on, in various fields and professions related to computing hardware and software and its applications. Remarkable efforts are being done in various walks of life to absorb this innovatory change and to make best use of the modern computing technologies and devices. For structural engineers also, it is need of the hour to embrace modernized computing techniques and devices in order to be able to provide quick answers to ever increasing real world problems. This paper has highlighted some of the areas where the structural engineering profession and the academia can make use of the new developments to facilitate the use of interactive computer applications. The paper also introduced three case study applications from various fields of structural engineering in order to demonstrate how effectively the benefits of software development can be exploited in terms of knowledge transfer as well as understanding of engineering concepts.

\section{ACKNOWLEDGMENT}

The authors are thankful to Dr. Naveed Anwar, Executive Director AIT Consulting, for his guidance during the development of various applications which are presented in this paper. We are also thankful to staff of NUST Institute of Civil Engineering (Pakistan) and AIT Consulting (Thailand) for providing excellent environment and research facilities.

\section{REFERENCES}

[1] B. Shneiderman, Leonardo's Laptop: Human Needs and the New Computing Technologies, Boston (MA), MIT Press, 2002.

[2] N. Anwar and A. Nawaz, "Advancements in computing tools and their application in structural engineering," in Proc. the 15th ASEP International Convention (15AIC). The Association of Structural Engineers of the Philippines, Inc. (ASEP) 28th - 29th September 2011

[3] E. J. Garboczi, D. P. Bentz, and G. J. Frohnsdorff, "Knowledge-based systems and computational tools for concrete," Concrete International, vol. 3, December 2000.

[4] N. Anwar, R. P. Pama, and J. Pathak, "Developing interactive, computer based learning tools for civil engineering students," in Proc. the International Conference on Civil Engineering Education (ICCEE2012), Manila, Philippines, 2012.

[5] M. K. Frank, L. F. Gregory, and S. H. Micheal, Open System for Earthquake Engineering Simulation, Pacific Earthquake Engineering Research Center, USA
[6] W. Cao, H. H. Cudney, and R. Waser, "Smart materials and structures," in Proc. Natl. Acad. Sci., vol. 96, pp. 8330-8331, July 1999.

[7] D. Hanselman and B. Littlefield, Mastering MATLAB 7, Pearson Education, Inc., Prentice Hall, New Jersey, USA, 2005

[8] W. J. Palm, Introduction to MATLAB 7 for Engineers, McGraw-Hill Science/Engineering/Math, 2003.

[9] M. Abdullahi, H. M. A. A. Mattarneh, and B. S. Mohammed, "A MATLAB program for diagnosis and adjustment of mix proportions of structural lightweight concrete," European Journal of Scientific Research, vol. 31, no. 1, pp. 106-123, Inc. 2009.

[10] M. Abdullahi, H. M. A. A. Mattarneh, and B. S. Mohammed, "Graphical user interface for proportioning lightweight concrete," Concrete international, vol. 3, 2009.

[11] P. Marchand and O. T. Holland, Graphics and GUIs with MATLAB, Third Edition, CHAPMAN and HALL/CRC, USA, 2003

[12] A. K. Chopra, Dynamics of Structures - Theory and Applications to Earthquake Engineering, Prentice Hall, Upper Saddle River, NJ, 2001.

[13] M. Srikanth, G. R. Kumar, and S. Giri, "Moment curvature of reinforced concrete beams using various confinement models and experimental validation," Asian Journal of Civil Engineering (Building and Housing), vol. 8, no. 3, pp. 247-265, 2007

[14] E. Hognestad, "A study of combined bending and axial load in reinforced concrete members," Engineering Experimental Station Bulletin, no. 399, Univ. of Illinois, 1951.

[15] J. G. Macgregor, Reinforced Concrete Mechanics and Design, Third Edition, Prentice Hall, Upper Saddle River, New Jersey 07458, ISBN 0-13-233974-9, USA, 1997.

[16] F. A. Najam and S. A. Rizwan, "Development and automation of an empirical mix proportioning method for concretes with indigenous aggregates and cements of Pakistan," in Proc. the International Conference on Advanced Concrete Technology \& Its Applications, (ACTA-2012), NUST, Islamabad, November 6-7, 2012, Pakistan.

[17] American Concrete Institute, "Committee 211 Report - Standard practice for selecting proportions for normal, heavyweight, and mass concrete," ACI Manual of Concrete Practice, 2005.

[18] Y. Bai and S. N. Amirkhanian, "Knowledge-based expert system for concrete mix design," Journal of Construction Engineering and Management, vol. 20, no. 2, pp. 357-73, 1994.

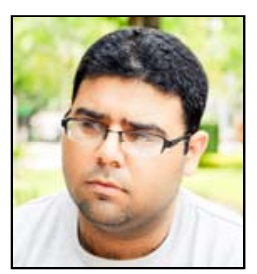

Fawad A. Najam is a current doctoral student at Asian Institute of Technology (AIT), Thailand. He received his BS degree in civil engineering from University of Engineering and Technology (UET, Taxila) and MS degree in structural engineering from National University of Sciences and Technology (NUST), Islamabad, Pakistan. His areas of interests include earthquake engineering and structural dynamics, seismic performance evaluation of tall buildings, structural engineering software development, numerical analysis, high-performance cementitious systems and finite element programming.

$\mathrm{He}$ has an experience of 5 years in academia working at various appointments including research associate, teaching assistant, laboratory engineer and lecturer of civil engineering at various academic institutes in Pakistan and Thailand. He has participated actively in various private and public sector projects strengthening the academia-industry linkages in Pakistan while working at National University of Sciences and Technology (NUST). Currently, he is associated with AIT Consulting, an international consulting and research organization at Asian Institute Technology (AIT) Thailand, creating a link between AIT and public by providing a wide range of consulting services in engineering, technology, environment, development and management. 